\title{
A case control study of modifiable risk factors of low birth weight among full term babies at Omdurman maternity hospital, Khartoum, Sudan 2019
}

Ethar Abdullah ( $\nabla$ ethar.majed.3@gmail.com )

University of Khartoum

Research Article

Keywords: Low birth weight, Sudan, risk factors

Posted Date: July 21 st, 2021

DOl: https://doi.org/10.21203/rs.3.rs-733127/v1

License: (c) (i) This work is licensed under a Creative Commons Attribution 4.0 International License.

Read Full License 


\section{A case-control study of Modifiable risk factors of low birth weight among full term babies at Omdurman maternity hospital, Khartoum, Sudan 2019}

\section{Submitted by:}

Ethar Abd-Allah Abd-Allah Abd AL-majid

Fifth year medical student Faculty of medicine university of Khartoum

\section{Supervisor:}

Dr. Zainab Mohammad Amara

MBBS UofK MD C.M

Contents:

Acronyms

Executive Summary

Chapter 1: Introduction

1 Background information

2 Problem statement

3 Justification

4 Objectives

4.1 General

4.2 Specific 


\section{Chapter 2: Literature review}

1 International studies

2 Regional

3 National

\section{Chapter 3: Methodology}

1 Study design

2 Study area

3 Study population

4 Study sample

5 Data collection

6 Variable

7 Data analysis

8 Ethical issues

9 Study limitations

\section{Chapter 4: Results}

1 Socio-economic and demographic factors:

2 Medical conditions and obstetric factors

3 Health care and life style factors

4 Mother's constitutional factors

\section{Chapter 5: Discussion}

\section{Chapter 6: Conclusion and Recommendations}

Conclusion

Recommendations

\section{References}

\section{Appendices}

Questionnaire 
Acronyms:

$\begin{array}{ll}\text { LBW } & \text { Low birth weight } \\ \text { NBW } & \text { Normal birth weight } \\ \text { IUGR } & \text { Intra-uterine growth restriction } \\ \text { SGA } & \text { Small for gestational age } \\ \text { IQ } & \text { Intelligence score } \\ \text { ANC } & \text { Anti-natal care } \\ \text { UTI } & \text { Urinary tract infection } \\ \text { BMI } & \text { Body mass index }\end{array}$


WHO World health organization

WHA World health assembly

UNICEF United Nations International Children's Emergency Fund

\section{Executive summary:}

\section{Introduction:}

Low birth weight (delivery of an infant with less than 2500 grams) is owed to two main causes, either IUGR or pre-term delivery. It makes the newborn susceptible to many health issues from birth and through the adulthood life. Whoever IUGR is the leading cause of LBW in developing countries, and hence it is more reliable here in Sudan to study the risk factors that lead to it which are whoever mostly modifiable.

\section{Methodology:}

This is a hospital based unmatched case-control study. A total of 134 (67 cases and 67 controls) mothers and their full-term newborn infants were included in the study. The participants were interviewed with a questionnaire and anthropometric measurements were obtained at the end of the interview. The data was analyzed using SPSS and Odd ratios of the risk factors were calculated. 


\section{Conclusion:}

The main risk factors that found to influence the birth weight of our study participants were: lack of maternal education, rural place of residence, bleeding during pregnancy, high blood pressure during pregnancy, inadequate spacing, lack of ANC follow up, not having iron supplementation and exposure to passive smoking during pregnancy.

\section{CHAPTER ONE}

\section{Introduction}

\section{Background information:}

Low birth weight (LBW) is defined by the World Health Organization as birth of an infant weighting less than 2500 grams. This is based on an epidemiological observation that infant weighting less than 2500 grams are more likely to die compared to heavier babies(1).

Low birth weight is an outcome of preterm birth, intrauterine growth restriction or combination of both. Preterm birth (before 37 weeks gestation) is the leading cause of LBW in developed countries, whereas small for gestational age is the leading cause in 
developing countries. Whoever most of factors that lead to small for gestational age are considerably avoidable.(2)

Small for gestational age children are full term neonates but they experience intrauterine growth restriction, i.e. they have failed to reach their full genetically determined growth and appear thin and malnourished.

Growth restriction has traditionally been classified as symmetrical or asymmetrical. In the more common asymmetrical growth restriction, the weight or abdominal circumference lies on a lower centile than that of the head. This occur when the placenta fails to provide adequate nutrition late in pregnancy but brain growth relatively spared at the expense of liver glycogen and skin fat. This form of growth restriction is associated with utero-placental dysfunction secondary to maternal pre-eclampsia, multiple pregnancies, maternal smoking or may be idiopathic. These infants rapidly put on weight after birth. Whoever, this is associated with an increased risk of obesity and type 2 diabetes in later life.

In symmetrical growth restriction the head circumference is equally reduced. It suggest long period of IUGR starting in early pregnancy. It is usually due to small but normal fetus or may be due to fetal chromosomal disorder or syndrome, maternal infection, drug use or alcohol abuse, a maternal chronic medical condition or malnutrition. These infants are more likely to remain small permanently.

\section{Problem Statement:}

Growth restricted fetus is at risk of intra-uterine hypoxia and unexplained intrauterine death. After birth, these infants are liable to hypothermia because of their relatively large surface area (especially their heads), hypoglycemia from poor fat and glycogen stores, hypocalcaemia, and polycythemia.

Small for gestational age (SGA) infants are also known to be at increased risk of mortality and several morbidities such as respiratory distress syndrome, necrotizing enterocolitis, late-onset sepsis, severe retinopathy of prematurity, and chronic lung disease and risk for severe intraventricular hemorrhage.(3). They also suffer from lower IQs compared to those with NBW(4). 
The consequences of low birth weight continue into adulthood, increasing the risk of adult onset chronic conditions such as obesity, diabetes and cardiovascular diseases(5).

20.5 million LBW babies born in 2015 which means one in every seven newborns.

During the 65th Africa was home to about one quarter of all those newborns.(6)

World Health Assembly (WHA) Member States endorsed the target of a 30 percent reduction in LBW globally between 2012 and 2025. However, reporting on progress remains a challenge because of paucity of data in some region of the world. Most data on LBW come from the more developed countries - yet these countries account for just under 5 per cent of all LBW births in 2015. Birth weight data were not available for nearly one third with Africa accounting for over half of these. In 2004 UNICEF global estimates prevalence of LBW in Sudan was found to be $31 \%$, but unfortunately in the 2015 UNICEF global estimates Sudan data was missed. (6)

\section{Justification:}

Understanding the role and causes of poor fetal growth as a cause of LBW is an important step in developing effective prevention programs. It is not necessary that all of them should be present in a given area. They vary from one area to another depending on geographic, socioeconomic, cultural factors and health care seeking behavior and services. In more developed regions, LBW is associated with prematurity and cesarean sections.

In less developed regions LBW is primarily caused by poor fetal growth as linked to poor maternal nutrition, anemia and other health issues (2), and hence here in Sudan it is more reliable to study the risk factors that restrict the intrauterine growth. In this study we will investigate the presence of selected modifiable determinant of LBW. The purpose of this study is to clarify the significance of those determinants on affecting newborns weight in Omdurman maternity hospital. The results of this study would contribute in developing a more goal directed preventive measures against LBW in the area covered by the hospital.

\section{Objectives}

\subsection{General objectives:}


To study the risk factors of low birth weight among singleton full term deliveries in Omdurman maternity hospital in 2019.

\subsection{Specific objectives:}

1- To assess the significance of impact of maternal socio-economic and demographic factors on their full-term newborns' weight at Omdurman maternity hospital.

2- To assess the significance of influence of selected medical conditions and obstetric factors on full-term newborns' weight at Omdurman maternity hospital.

3-To assess the significance of influence of mothers' health care utilizing behavior and life style on their newborns' weight.

4-To assess the significance of mothers' constitutional factors on their full-term newborns' weight at Omdurman maternity hospital.

\section{CHAPTER TWO}

\section{Literature Review}

There is considerable variation in the prevalence(1) and causes(2) that lead to LBW across regions and within countries. Regional estimates of low birth weight include $28 \%$ in south Asia, 13\% in sub-Saharan Africa and 9\% in Latin America (1). It is worth noting that these rates are high, in spite of the fact that the data on low birth weight remain limited to some regions, as many deliveries are not reported in official figures.

\section{Low birth weight categories:}

LBW neonates are either preterm neonates, small for gestational age neonates and the overlap between these two situations. These three groups have their own subgroups, with different causative factors and their distributions across populations that depend 
on the prevalence of the underlying causal factors. While preterm-birth is considering as the leading cause of LBW in developed countries, IUGR is the leading cause of it in developing countries(2). Understanding and differentiating the various categories and their causes is an essential first step in preventing these conditions and hence the importance of a risk factor is the function of the prevalence of exposure to that factor in a specific population setting. In this literature review we are concerned with investigating and compare the significant of existing of LBW risk factors that are reported in these studies in term but small for gestational age category which are more responding to preventive measures.

\section{International Studies:}

India

1) A case-control study was conducted in a tertiary care government hospital in Solapur, Maharashtra, India, 2015 (7). A total of 220 cases and 220 controls. Significant socio-demographic variables associated with LBW in this study were; Age of mother $<20$ or $>30$ years which align with many other studies in that mothers who are less than 20 years of age or teenage mothers overall have an increasing incidence of delivering a LBW infants (8),(9).

Other significant factors in this study were maternal education (illiterate/primary), mother height $<145 \mathrm{~cm}$ as in 2 studies from Nepal and Ethiopia (8),(10), which may be owed to small age or stunted growth due to poor nutritional status and both of these play an additional negative impact on newborn growth, maternal occupation (laborer) and lower socioeconomic status. Also spacing <2 years between pregnancies, pregnancy-induced hypertension, tobacco exposure, , pre-pregnancy weight $<45 \mathrm{~kg}$, primigravida (pregnant for the first time), anemia, inadequate $\mathrm{ANC}$ as late antenatal care (ANC) registration were identified as significant risk factors for LBW neonates.

2) A retrospective record-based study, carried out at the Dr. P.K Charitable Hospital of Belgaum district, South India, 2014(11), among 1299 women delivered singleton live births at full term significant factors associated with the LBW were primigravia 
which is consistent with(12),(7),(13), and hypertensive mothers which is consistent with (7), (14).

3) Demographic surveillance over 12 years helps elicit determinants of low birth weights in India in 2019 (15), low birth weight was found to be associated with first birth order (primagravida), poor maternal education and occupation as cultivation.

4) A case control study was done involving 200 cases and 200 controls in a tertiary care hospital of Indore District, India in 2017(16). Socio economic variables affecting birth weight were place of residence and maternal age (under 20). Maternal variables affecting LBW were maternal anemia, complications during pregnancy, weight gain of the mother and maternal height. The health care utilization parameters affecting LBW were timing of registration of pregnancy, adequate number of ANC visits wich consistent with many studies (8),(17),(16),(18), and consumption of IFA tablets.

\section{$\underline{\text { Pakistan }}$}

5) A cross-sectional study among women who gave birth to babies with less than 2500gm in a general hospital, Karachi, Pakistan in 2016 (21), LBW was found to be associated with low socio-economic status, anaemia, primiparity, short maternal height and less than average weight.

\section{$\underline{\text { Nepal }}$}

6) A hospital-based retrospective case control study was conducted in Nepal in 2015

(8). Regression analysis revealed that a history of hard physical work during pregnancy, younger age of mother, mothers with haemoglobin level less than $11 \mathrm{gm} / \mathrm{dl}$, and lack of consumption of nutritious food during pregnancy were significantly associated with the birth of LBW babies

7) An unmatched case control study was done involving 159 cases and 159 controls in eastern Nepal to assess the maternal and socio-demographic factors associated with low birth weight (LBW) babies 2015(14), More than 50\% of LBW babies were from the mothers with height $\leq 145 \mathrm{~cm}$ while only $9.43 \%$ of NBW babies were from the mothers with that height. Also, time of first antenatal care (ANC) visit, number of ANC visits, iron supplementation, calcium supplementation, maternal education, any 
illness during pregnancy, and hypertension were found as the significant predictors of LBW.

\section{Regional studies:}

\section{Ethiopia}

8) In a case-control study about determinant of LBW in referral hospital in Ethiopia in 2018 (22) a total of 147 birth records of babies with low birth weight (cases) and 294 birth records of babies with normal birth weight (controls) were reviewed. Babies born to mothers who had history of any sign of pregnancy complications (any one or more of bleeding, gush, headache, blurred vision, fever, and severe abdominal pain) were about three times more likely to have low birth weight as compared to babies born to mothers who did not have such history. Maternal history of chronic diabetes was found to have negative relationship with low birth weight. In this regard, babies born to mothers having history of chronic diabetes mellitus were $72 \%$ less likely to have low birth weight as compared to those born to mothers with no history of chronic diabetes mellitus.

9) 432 postpartum women with their term newborns were involved in a case-control study to investigate the risk factors of LBW in Wolaita Sodo town in south Ethiopia in 2016(23). Women who had less education, housewives and not frequently consuming fruits during pregnancy had a higher risk of having term low birth weight newborns. Rural settings have low birth weight newborns as compared to their counter urban equivalents.

10) An institution based comparative cross-sectional study conducted in Ethiopia in 2014 (24), a sample of 520 live birth neonates were selected from both urban and rural districts. The prevalence of low birth weight was $9.9 \%$ and $6.3 \%$ in urban and rural districts respectively. This finding is in contrast to another two studies in Ethiopia (23) and (25) wish stated that low birth weight was associated with rural place of residence .This was explained by the finding that in that urban district there was inadequate ANC service utilization. 
11) Another Across-sectional study in Adwa General Hospital, Northern Ethiopia in 2017 (9) showed that maternal age, hemoglobin status, iron folic acid intake, and HIV status were significantly associated with term low birth weight. Mothers less than 20 years of age delivering at the hospital were most likely to have term low birth weight, which is in agreement with studies done in Nepal (8) and Ethiopia (26). Anemic mothers were likely to have low birth weight babies compared to non-anemic mothers; this is similar to results of studies from Pakistan (21).

12) Across sectional study in Gondar town, Ethiopia2014 (26) stated that pregnancyinduced hypertension and malaria attack during pregnancy significantly associated with LBW in the area.

13) A case-control study(136 cases and 272 controls) in Bale Zone hospital south-east Ethiopia in 2015 (10) revealed that, maternal age at delivery <20 years, monthly income <26 United States Dollar (USD), lack of formal education and residing in rural area were socio-economic variables associated with low birth weight, Maternal risk factors were occurrence of health problems during pregnancy, maternal body mass index $<18 \mathrm{~kg} / \mathrm{m} 2$, maternal height $<1.5 \mathrm{~m}$, inter-pregnancy interval $<2$ years and absence of antenatal care were associated with low birth weight.

14) A cross-sectional mixed study was carried out in 3 zonal hospitals among 308 mothers 2015 (25) low birth weight was associated with rural place of residence, presence of any chronic medical illness, and maternal weight $<50 \mathrm{~kg}$.

\section{Ghana}

15) In a cross-sectional study about socio-demographic determinants of LBW in Ghana in 2017(27), 8,263 live births were included, the prevalence of LBW were $13.8 \%$. . Determinants of low birth-weight were maternal age and mothers who are not married. Mothers in the 20-34-year age group were less likely to have neonates with LBW compared to those below 20 years, this is considerably similar to a conclusion of a research from Brazil showing protection for low birth weight between ages $\geq 18$ years and $<35$ years (28) and India(7) , also LBW neonate was $35 \%$ lower among women who were 35 years and above when compared to the under 20 years 
group. Socio-economic condition as measured in this study was an important risk factor for LBW as identified by other studies in similar settings (29), (12).

16) A study in southern rural Ghana a bout demographic and socio-economic determinants of LBW among 6777 women 2016 (12) concluded that women aged 2034 years were more than twice more likely to have babies weighing $\geq 2.5 \mathrm{~kg}$ compared to those $<20$ years, and mothers who were $>34$ years were more than three times more likely to have babies weighed $\geq 2.5 \mathrm{~kg}$ and those results are similar to(27),(28),(7) and differ from (19). Mothers who were civil servants were $77 \%$ more likely to have babies weighed $\geq 2.5 \mathrm{~kg}$ compared to those who were unemployed. Mothers from poorer households were $30 \%$ more likely to have heavier babies compared to those from the poorest households. Women with parity 2 and parity $>3$ were $30 \%$ and $81 \%$ more likely to have babies weighing $\geq 2.5 \mathrm{~kg}$ compared to those with parity 1 , so they stated that primagravida have a higher risk of delivering LBW babies this is similar to (7).

\section{$\underline{\text { Congo }}$}

17) Risk factors of LBW in Mbujimayi City, Democratic Republic of Congo in 2017 (30) were, multiparity this contrast with (7),(30),(13).

Unmarried women, anemia of pregnancy, diabetic mothers and the history of malaria were also found to be significant LBW risk factors in this study.

\section{$\underline{\text { Nigeria }}$}

18) A cross-sectional survey study from Nigeria 2016(13) highlighted the following factors as significant causes of LBW: mothers ages 15-24 years, mothers without formal education, primiparous mother and maternal weight of less than $70 \mathrm{~kg}$. There was also significant association between paternal educational level and LBW.

\section{$\underline{\text { Morocco }}$}

19) $98 \mathrm{LBW}$ cases matched to 98 control children in a study about LBW determinants in Morocco 2015 (17). maternal age (35 years and over), women who had over three 
pregnancies(multiparous), hypertensive pregnancy, anemia, mother stature less than $150 \mathrm{~cm}$ and inadequate ANC visits were found to be associated with LBW outcome. socio-economic factors assessed in this study consider the standard of living of families did not have any effect on the LBW in contrast to (29), (12), (27) which established the negative role of low income on birth weight, they explain this by the homogeneity of the studied group since the majority of mothers (70.9\%) belong to low-income families.

20) Secondary data analysis was conducted using 10 recent Demography and Health Surveys from developing countries 2017 (18), factors that shown to have a significant association with LBW infant in developing countries are : maternal age of 35 to 49 years, inadequate antenatal care (ANC), illiteracy, delayed conception, low body mass index, and being in the poorest socioeconomic stratum

\section{National}

\section{$\underline{\text { Sudan }}$}

21) In a cross sectional study of 381 women about risk factors of low birth weight at three hospitals in Khartoum State, Sudan 2014 (20), 13\% of live born children were of low birth weight. The main risk factors for low birth weight in the study were the lack of adequate education, presence of hypertension, bleeding during pregnancy and presence of moderate or severe anemia. While Adequacy of antenatal care (ANC) visits in contrast to (18), (16), (17), presence of diabetes mellitus during pregnancy same as (22), smoking and malaria in the first three trimesters, presence of previous children and spacing were all found to be statistically not significant risk factors.

22) Another study carried out in Omdurman maternity hospital, Khartoum, Sudan 2015 (19), no significant correlation was found between weight of new born and maternal age despite the strong association in other studies . It was observed that, low birth weight was more prevalent among the mothers of age group between 20-30 years, this was not in line with many other studies which proved that pregnancy of mothers of less than 20 years have increased risk of low birth weight infants(8), (7), (9). This study also revealed that infants born to women who conceived less than six 
months after giving birth had increased risk of low birth weight, compared with infants born to mothers who waited 18 months to 2 years between pregnancies, so they suggest that better pregnancy spacing could have a dramatic impact on birth outcome in contrast to other study done in Khartoum which ignore the role of adequate spacing(20). Significant correlation was found between weight of new born and presence of hypertension, urinary tract infections and malaria during pregnancy. Mothers who took supplements (folic acid and iron) appeared to have low percentage of LBW babies. Primagravida mothers were comparatively at lower risk of delivering LBW babies this differ from (7), (30), (13) which link LBW to primagravida mothers. A significant correlation was found between LBW newborns and underweight mothers.

No significant correlation was found between weight of newborn and the occurrence of bleeding during pregnancy or adequacy of ANC visits.

\section{CHAPTER THREE}

\section{Materials and Methods}

1. Study Design: The study was conducted using unmatched case-control design.

2. Study Area: Omdurman Maternity Hospital had been established in the year 1957 as the first specialized hospital in Sudan, for the purpose of providing more care and medical services to mothers and newly born babies. Also, it is considered to be the main training center for the midwives. It is located in South Western area of Omdurman. At the beginning, it started with one building for delivery with 34 beds. Different sections had been then added to the first building, such as nursery of the 
newly born infants in 1977, the major operation theater in 1979, sterilization room in 1982, and private rooms in 1993.

The hospital contains 8 delivery wards- 6 general and 2 private- with 354 beds, 5 gynecology wards with 57 beds, an ICU unit and a nursery ward with 64 beds 18 of them are incubators.

\section{Study Population:}

Women who delivered at Omdurman maternity hospital and their babies during the period of the study.

Controls: mothers who gave birth to normal birth weight babies ( $>$ or $=2500$ grams) and their newborns.

Cases: mothers who gave birth to low birth weight babies $(<2500$ grams $)$ and their newborns.

Inclusion criteria: mothers who gave birth to full term singleton newborn.

Exclusion criteria: any newborn with congenital malformation, severely ill mothers who could not participate and mothers who are unwilling to participate.

\section{Study Sample}

The sample size was estimated using Fleiss method: Two sided confidence level: 95, Power: 80, Ratio of control to cases: 1:1, Percent of controls exposed: 20\%, Odd ratio: 3 , Percent of cases with exposure: $43 \%$.

With considering the non-respondance rate is 5\%: cases 67 and control 67, total sample size is 134 .

\section{Data Collection:}

\section{$1.5 \backslash \underline{\text { Data collection tools: }}$}

1- Questionnaires. 
2- Measuring tape to measure Mothers' height.

3- Weighting scale to measure Mothers' weight.

\section{$2.5 \backslash$ Methods of data collection:}

1-Interview following structural questions which include:

A- Information about socio demographic variables.

B- Medical and obstetric information.

C- Health care and life style factors.

2- Anthropometric measurements include:

A- Height of the mothers.

B- Weight of the mothers.

C- Weight of the babies from the hospital records.

\section{Variables:}

Socio-demographic variables: mother's age, marital status, mother's age at marriage, mother's educational level, mother's occupation, father' educational level, residency, monthly income and activities during pregnancy.

Medical conditions during pregnancy and obstetric factors:, bleeding, high blood pressure, diabetes, malaria, fever, urinary tract infection, number of previous deliveries (parity), mother's age at first delivery and inter-pregnancy intervals (spacing).

Health care and life style factors: anti-natal care ANC follow up, folic acid and Iron supplements, active smoking during pregnancy and exposure to passive smoking during pregnancy.

Anthropometric measurements: newborn's weight in grams, mother's weight in kilograms, mother's height in meters and mother's body mass index BMI $(\mathrm{kg} / \mathrm{m} 2)$

\section{Data Analysis:}

The data was entered and statistical analyses were performed using Statistical Package for Social Sciences (SPSS) version 25 program.

Descriptive statistics (frequencies and percentages) for different determinants were carried out by cross-tabulation and presented in tables. 
Then we screen all the potential determinants for relationship with the dependent variable (birth weight) using univariate logistic regression test (goodness of fit), pvalues, odd ratios and confidence intervals were determined.

Paired-sample t-test was used to compare means of categorical variables between cases and controls.

\section{Ethical Issues:}

- Approval of the department of community medicine, Faculty of medicine, U of K.

- Approval of the Federal Ministry of Health.

- Permission from Omdurman maternity hospital authority.

-Verbal consents were obtained from mothers to participate.

\section{Study Limitations:}

This was a small hospital based study intended to explore the risk factors of LBW in Omdurman maternity hospital and to some extent the area covered by it. The small sample size and difficulty of measuring some of the risk factors- like mothers' nutritional status and anemia during pregnancy due to lack of ANC follow up reports might account for the failure of finding significant associations of some of the risk factors.

\section{CHAPTER FOUR}

\section{Results}

\section{$\underline{\text { Socio-economic and demographic characteristics of the respondants: }}$}

A total sample of 134 mothers comprising 67 cases and 67 controls were included in the study. Majority of the respondents (82.8\%) were of 20 to 35 years, while (8.2\%) were teenagers (less than 20 years old) and (9\%) were above 35 years old. (41\%) received primary or no education, nearly two-third (62.5\%) of them were cases. All the respondents were married and almost all (90.3\%) were not occupied (house wives). (25.4\%) of the participants were from rural area -with cases comprising 
$(79.4 \%)$ of them-, while $(74.6 \%)$ of total were from urban area. Out of the total sample $(35.1 \%)$ had low monthly income, $(39.6 \%)$ had moderate monthly income and (25.4\%) had high monthly income.

Table(1): General description in terms of frequencies and percentages of characteristics of the participants in the study about risk factors of LBW at Omdurman Maternity Hospital in 2019. n= 67 cases, 67 controls

\begin{tabular}{|c|c|c|c|}
\hline & $\begin{array}{c}\text { Cases } \\
\mathrm{N} \text { (\% within } \\
\text { total) }\end{array}$ & $\begin{array}{c}\text { Controls } \\
\mathrm{N} \text { (\% within } \\
\text { total) }\end{array}$ & $\begin{array}{l}\text { Total } \\
\text { N (\%) }\end{array}$ \\
\hline $\begin{array}{l}\text { Mother's age group: } \\
\text {-Less than } 20 \text { years } \\
\text {-20-35 years } \\
\text {-More than } 35 \text { years }\end{array}$ & $\begin{array}{c}7(5.2) \\
54(40.3) \\
6(4.5)\end{array}$ & $\begin{array}{c}4(3) \\
57(42.5) \\
6(4.5)\end{array}$ & $\begin{array}{c}11(8.2) \\
111(82.8) \\
12(9)\end{array}$ \\
\hline $\begin{array}{l}\text { Mother's education } \\
\text {-primary or no education } \\
\text {-secondary or above }\end{array}$ & $\begin{array}{l}35(26.1) \\
32(23.9)\end{array}$ & $\begin{array}{l}21(15.7) \\
46(34.3)\end{array}$ & $\begin{array}{l}56(41.8) \\
78(58.2)\end{array}$ \\
\hline $\begin{array}{l}\text { Marital status } \\
\text {-Married } \\
\text {-Divorced } \\
\text {-Widow } \\
\text {-Single }\end{array}$ & $\begin{array}{l}67(50) \\
0(0) \\
0(0) \\
0(0)\end{array}$ & $\begin{array}{l}67(50) \\
0(0) \\
0(0) \\
0(0)\end{array}$ & $\begin{array}{c}134(100) \\
0(0) \\
0(0) \\
0(0)\end{array}$ \\
\hline $\begin{array}{l}\text { Mother's occupation } \\
\text {-Not occupied } \\
\text {-Occupied }\end{array}$ & $\begin{array}{c}63(47) \\
4(3)\end{array}$ & $\begin{array}{c}58(43.3) \\
9(6.7)\end{array}$ & $\begin{array}{c}121(90.3) \\
13(9.7)\end{array}$ \\
\hline $\begin{array}{l}\text { Residency } \\
\text {-Urban } \\
\text {-Rural }\end{array}$ & $\begin{array}{l}40(29.9) \\
27(20.1)\end{array}$ & $\begin{array}{c}60(44.8) \\
7(5.2)\end{array}$ & $\begin{array}{c}100(74.6) \\
34(25.4)\end{array}$ \\
\hline $\begin{array}{l}\text { Monthly income } \\
\text {-high } \\
\text {-moderate } \\
\text {-low }\end{array}$ & $\begin{array}{l}15(11.2) \\
24(17.9) \\
28(20.9)\end{array}$ & $\begin{array}{l}19(14.2) \\
29(21.6) \\
19(14.2)\end{array}$ & $\begin{array}{l}34(25.4) \\
53(39.6) \\
47(35.1)\end{array}$ \\
\hline
\end{tabular}


There was no significant difference in the maternal age between cases and controls neither at current delivery $(\mathrm{p}=.779)$, at marriage $(\mathrm{p}=.843)$ nor at the first delivery $(\mathrm{p}=.825)$ for multiparous mothers.

Mother's education $(\mathrm{p}=.015)$ and place of residency $(\mathrm{p}=.001)$ were found to be significantly associated with LBW. The mothers who received primary or no education were two times ( $\mathrm{OR}=2.396,95 \% \mathrm{CI}$ : 1.184- 4.856) more likely to deliver LBW neonates than the mothers who received secondary or above education, and those who resided in rural area were ten times ( $\mathrm{OR}=10.309,95 \% \mathrm{CI}: 2.717-39.123$ ) more likely to deliver LBW neonates than those who resided in urban area.

Mother's occupation ( $\mathrm{p}=.353)$, father's education $(\mathrm{p}=.153)$, monthly income $(\mathrm{p}=.064)$ and physical activities during pregnancy $(\mathrm{p}=.549)$ were found to be insignificant.

Medical conditions during current pregnancy and obstetric factors:

Mothers having fever $(\mathrm{p}=.261)$, malaria $(\mathrm{p}=467)$ and diabetes $(\mathrm{p}=.535)$ during pregnancy were not significantly associated with LBW babies. But high blood pressure $(\mathrm{p}=.003)$ vaginal bleeding $(\mathrm{p}=.032)$ and UTI $(\mathrm{p}=.023)$ were found to be significant.

Mothers having hypertension during pregnancy were eight times more likely to deliver LBW neonates than mothers having no hypertension $(\mathrm{OR}=8.740,95 \% \mathrm{CI}$ : 2.101-36.363), and mothers having vaginal bleeding during pregnancy were seven times $(\mathrm{OR}=7.271,95 \% \mathrm{CI}$ : $1.184-44.633)$ more likely to give birth to LBW neonate than mothers who do not experienced this during pregnancy. While having UTI during pregnancy appeared as having a protective effect against LBW, as mothers who had been diagnosed with UTI during pregnancy were two times $(\mathrm{OR}=2.257$, 95\% CI: 1.119-4.566) less likely to give birth to LBW neonates.

There were no significant association with having LBW neonate and being primagravida or multigravida $(\mathrm{p}=.484)$, but spacing was significantly associated with LBW. Mothers who kept inter-pregnancy intervals of 2 years or more were five times $(\mathrm{OR}=5.106,95 \%$ CI: $1.263-20.650)$ less likely to deliver LBW neonate

$\underline{\text { Health care and life style factors: }}$ 
Antenatal care (ANC) visits $(\mathrm{p}=.042)$ were significantly associated with LBW.

Mothers who followed up their pregnancy with ANC visits were less likely to deliver LBW infants than mothers who did not follow up (OR= .112, 95\% C.I: .014- .920). Iron supplementation $(\mathrm{p}=.014)$ was found to be significantly associated with LBW. The mothers who were supplemented with iron were nearly fivefold $(\mathrm{OR}=5.181$, 95\% CI: 1.393-19.230) unlikely to have LBW babies than the mothers who were not having iron supplementation. Exposure to passive smoking $(\mathrm{p}=.009)$ was significantly associated with LBW. Mothers who were exposed to passive smoking during pregnancy were five times $(\mathrm{OR}=5.635,95 \% \mathrm{CI}$ : $1.537-20.656)$ more likely to give birth to LBW neonate.

Folic acid supplementation $(\mathrm{p}=.893)$ and active smoking $(\mathrm{p}=.999)$ during pregnancy were found to be insignificant.

Mother's constitutional factors:

Mothers' weight $(\mathrm{P}=.589)$, height $(\mathrm{p}=.462)$ and body mass index BMI $(\mathrm{p}=.602)$ were found to be insignificant. There were no significant differences in the means and standard deviations of those factors between cases and controls.

\section{Tables:}

Table (2): Mothers' ages at different occasions and constitutional factors of the participants in the study about risk factors of LBW at Omdurman Maternity Hospital in 2019. $n=67$ cases, 67 controls

\begin{tabular}{|l|c|c|c|}
\hline characteristic & $\begin{array}{c}\text { Case } \\
\text { Mean(standard } \\
\text { deviation) }\end{array}$ & $\begin{array}{c}\text { Control } \\
\text { Mean(standard } \\
\text { deviation) }\end{array}$ & p-value \\
\hline $\begin{array}{l}\text { Newborn's weight } \\
\text { in grams }\end{array}$ & $1973(349)$ & $3091(314)$ & $<.001 *$ \\
\hline
\end{tabular}




\begin{tabular}{|l|c|c|c|}
\hline $\begin{array}{l}\text { Mother's weight } \\
\text { in kg }\end{array}$ & $64(17.6)$ & $65.6(14)$ & .589 \\
\hline $\begin{array}{l}\text { Mother's height } \\
\text { in cm }\end{array}$ & $156.4(7.9)$ & $157.6(8.6)$ & .462 \\
\hline $\begin{array}{l}\text { Mother's BMI } \\
\text { Kglcm2 }\end{array}$ & $25.9(6)$ & $26.5(5.7)$ & .602 \\
\hline $\begin{array}{l}\text { Mother's age } \\
\text { mother's age at } \\
\text { marriage }\end{array}$ & $19.5(4.8)$ & $27.4(6.3)$ & .779 \\
\hline $\begin{array}{l}\text { Mother's age at } 1^{\text {st }} \\
\text { delivery }\end{array}$ & $21(5.4)$ & $19.3(3.9)$ & .843 \\
\hline
\end{tabular}

*Significant t-test at $\mathrm{p}<0.05$.

Table (3): Socio-economic and demographic characteristics of the participants in the study about risk factors of LBW at Omdurman Maternity Hospital in 2019. n= 67 cases, 67 controls

\begin{tabular}{|c|c|c|c|c|c|}
\hline & $\begin{array}{c}\text { Cases } \\
\mathrm{N} \text { (\%within } \\
\text { cases })\end{array}$ & $\begin{array}{l}\text { Controls } \\
\mathrm{N}(\% \text { within } \\
\text { controls })\end{array}$ & $\overline{p \text {-value }}$ & $\overline{\mathrm{OR}}$ & 95\% C.I. \\
\hline $\begin{array}{l}\text { Mother's age group: } \\
\text { Less than } 20 \text { years } \\
20-35 \text { years } \\
\text { More than } 35 \text { years }\end{array}$ & $\begin{array}{l}7(10.4) \\
54(80.6) \\
6(10.5)\end{array}$ & $\begin{array}{c}4(6) \\
57(85.5) \\
6(10.5)\end{array}$ & .929 & .947 & $.288-1.118$ \\
\hline $\begin{array}{l}\text { Mother's education } \\
\text { primary or no education } \\
\text { secondary or above }\end{array}$ & $\begin{array}{c}35(52) \\
32(47.8)\end{array}$ & $\begin{array}{l}21(34.4) \\
46(68.7)\end{array}$ & $.015^{*}$ & 2.396 & 1.184- 4.856 \\
\hline $\begin{array}{l}\text { Mother's occupation } \\
\text {-Not occupied } \\
\text {-Occupied }\end{array}$ & $\begin{array}{c}63(94) \\
4(6)\end{array}$ & $\begin{array}{c}58(86.6) \\
9(13.4)\end{array}$ & .257 & .353 & $.353-2.142$ \\
\hline
\end{tabular}




\begin{tabular}{|c|c|c|c|c|c|}
\hline $\begin{array}{l}\text { Father's education } \\
\text {-primary or no education } \\
\text {-secondary or above }\end{array}$ & $\begin{array}{l}31(46.3) \\
36(53.7)\end{array}$ & $\begin{array}{l}26(38.8) \\
41(61.2)\end{array}$ & .153 & .434 & $.139-1.362$ \\
\hline $\begin{array}{l}\text { Residency } \\
\text {-Urban } \\
\text {-Rural }\end{array}$ & $\begin{array}{l}40(59.7) \\
27(40.3)\end{array}$ & $\begin{array}{c}60(89.6) \\
7(10.4)\end{array}$ & $.001 *$ & 10.309 & $2.717-39.123$ \\
\hline $\begin{array}{l}\text { Monthly income } \\
\text {-high } \\
\text {-moderate } \\
\text {-low }\end{array}$ & $\begin{array}{l}15(22.4) \\
24(35.8) \\
28(41.8)\end{array}$ & $\begin{array}{l}19(28.4) \\
29(43.3) \\
19(28.4)\end{array}$ & .064 & 3.680 & $.926-14.629$ \\
\hline $\begin{array}{l}\text { Activities during } \\
\text { pregnancy } \\
\text { Very stressful } \\
\text { moderately stressful } \\
\text { mildly or not stressful }\end{array}$ & $\begin{array}{l}11(16.4) \\
12(17.9) \\
44(65.7)\end{array}$ & $\begin{array}{l}11(16.4) \\
13(19.4) \\
43(67.2)\end{array}$ & .549 & 1.514 & $.390-5.871$ \\
\hline
\end{tabular}

*Significant $\mathrm{p}$-value, significant odd ratio and confidence interval in bold. $\mathrm{OR}=\mathrm{Odd}$ ratio, $\mathrm{CI} .=$ Confidence interval.

Table (4): Medical conditions during current pregnancy and obstetric factors of the participants in the study about risk factors of LBW at Omdurman Maternity Hospital in 2019. $n=67$ cases, 67 controls

\begin{tabular}{|l|c|c|c|c|c|}
\hline & $\begin{array}{c}\text { Cases } \\
\text { N(\%within } \\
\text { cases) }\end{array}$ & $\begin{array}{c}\text { Control } \\
\text { N(\%within } \\
\text { controls) }\end{array}$ & p-value & OR & 95\% C.I. \\
\hline $\begin{array}{l}\text { vaginal bleeding } \\
\text {-yes } \\
\text {-no }\end{array}$ & $11(16.4)$ & $\begin{array}{c}3(4.5) \\
64(95.5)\end{array}$ & $.032^{*}$ & $\mathbf{7 . 2 7 1}$ & $\mathbf{1 . 1 8 4 - \mathbf { 4 4 . 6 3 3 }}$ \\
\hline $\begin{array}{l}\text { hypertension } \\
\text {-yes } \\
\text {-no }\end{array}$ & $17(25.4)$ & $\begin{array}{c}5(7.5) \\
62(92.5)\end{array}$ & $.003 *$ & $\mathbf{8 . 7 4 0}$ & $\mathbf{2 . 1 0 1 - 3 6 . 3 6 3}$ \\
\hline $\begin{array}{l}\text { diabetes } \\
\text {-yes } \\
\text {-no }\end{array}$ & $\begin{array}{c}2(74.6) \\
\text { malaria }\end{array}$ & $\begin{array}{c}2(3) \\
65(97)\end{array}$ & .535 & 2.171 & $.188-25.083$ \\
-yes & $9(13.4)$ & $\begin{array}{c}9(13.4) \\
58(86.6)\end{array}$ & .467 & .541 & $.103-2.835$ \\
\hline
\end{tabular}




\begin{tabular}{|c|c|c|c|c|c|}
\hline- no & & & & & \\
\hline $\begin{array}{l}\text { fever } \\
\text {-yes } \\
\text {-no }\end{array}$ & $\begin{array}{l}18(26.9) \\
49(73.1)\end{array}$ & $\begin{array}{l}15(22.4) \\
52(77.6)\end{array}$ & .261 & 2.244 & $.459-9.181$ \\
\hline $\begin{array}{l}\text { UTI } \\
\text {-yes } \\
\text {-no }\end{array}$ & $\begin{array}{l}21(31.3) \\
46(68.7)\end{array}$ & $\begin{array}{l}34(50.7) \\
33(49.3)\end{array}$ & $.023^{*}$ & 2.257 & $1.119-4.566$ \\
\hline $\begin{array}{l}\text { gravidity } \\
\text {-primagravida } \\
\text {-multigravida }\end{array}$ & $\begin{array}{l}17(25.4) \\
50(74.6)\end{array}$ & $\begin{array}{l}22(32.8) \\
45(67.2)\end{array}$ & .484 & 1.535 & $.463-5.095$ \\
\hline $\begin{array}{l}\text { spacing } \\
2 \text { years or } \\
\text { more } \\
\text { Less than } 2 \\
\text { years }\end{array}$ & $\begin{array}{l}48(71.6) \\
19(28.4)\end{array}$ & $\begin{array}{l}59(88.1) \\
8(11.9)\end{array}$ & $.022 *$ & 5.106 & $1.263-20.650$ \\
\hline
\end{tabular}

*Significant p-value, significant odd ratio and confidence interval in bold. OR= Odd ratio, CI.= Confidence interval.

Table (5): Health care and life style factors during pregnancy of the participants in the study about risk factors of LBW at Omdurman Maternity Hospital in 2019. n= 67 cases, 67 controls

\begin{tabular}{|c|c|c|c|c|c|}
\hline & $\begin{array}{c}\text { Cases } \\
\text { N(\%within } \\
\text { cases })\end{array}$ & $\begin{array}{c}\text { Control } \\
\text { N(\%within } \\
\text { controls })\end{array}$ & p-value & OR & 95\% C.I. \\
\hline $\begin{array}{l}\mathbf{A N C} \\
\text {-yes } \\
\text {-no }\end{array}$ & $\begin{array}{c}59(88.1) \\
8(11.9)\end{array}$ & $\begin{array}{c}66(98.5) \\
1(1.5)\end{array}$ & $.042 *$ & .112 & .014- .920 \\
\hline $\begin{array}{l}\text { Folic acid } \\
\text { supplements } \\
\text {-yes } \\
\text {-no }\end{array}$ & $\begin{array}{c}51(67.1 \%) \\
16(23.9)\end{array}$ & $\begin{array}{l}52(77.6) \\
15(22.4)\end{array}$ & .893 & 1.060 & $.458-2.453$ \\
\hline $\begin{array}{l}\text { Iron } \\
\text { supplement } \\
\text {-yes } \\
\text {-no }\end{array}$ & $\begin{array}{c}54(80.6) \\
13(19.4 \%)\end{array}$ & $\begin{array}{c}64(95.5) \\
3(4.5)\end{array}$ & $.014^{*}$ & 5.181 & 1.393- 19.230 \\
\hline
\end{tabular}




\begin{tabular}{|l|c|c|c|c|c|}
\hline Active smoking & $2(3)$ & $0(0)$ & .999 & .991 & $.189-5.207$ \\
-yes & $65(97 \%)$ & $67(100)$ & & & \\
\hline $\begin{array}{l}\text { Passive } \\
\text { smoking } \\
\text {-yes } \\
\text {-no }\end{array}$ & $14(21)$ & $\begin{array}{c}3(4.5) \\
64(95.5)\end{array}$ & $.009 *$ & $\mathbf{5 . 6 3 5}$ & $\mathbf{1 . 5 3 7 - 2 0 . 6 5 6}$ \\
\hline
\end{tabular}

*Significant p-value, significant odd ratio and confidence interval in bold. OR= Odd ratio, $\mathrm{CI} .=$ Confidence interval.

\section{CHAPTER FIVE}

\section{Discussion}

In this study an attempt has been made to determine the associated factors of low birth weight in Omdurman maternity hospital and the area covered by the hospital.

Results of this study revealed that maternal education, residence, vaginal bleeding, hypertension, UTI, spacing, ANC follow up, iron supplementation and exposure to passive smoking during pregnancy were found to be significant predictors for low birth weight. 
Maternal age had no significant association with LBW; this is in consistent with a study conducted by Somiya GSM. in 2015 in Omdurman maternity hospital, Khartoum, Sudan(19) which observed that, low birth weight was more prevalent among the mothers of age group between 20-30 years. But in contrast to many other studies which proved that pregnancy of mothers of less than 20 years (teenage mothers) have increased risk of low birth weight infants(8), (7), (9).

Residing in rural area was found to increase the risk of delivering a LBW neonate ten folds. This finding agrees with similar study findings from Tigray (Northern Ethiopia)(25) and Bale (South east Ethiopia) hospitals(24) in Ethiopia and also findings from India (32). This could be due to the accessibility of medical services, health information, and nutritional awareness which are more prominent as the woman resides in urban area than rural area, also this may be owed to the difference in socio-economic status and the degree of physical stress of mothers, between the two settings of residence.

Being non educated or of just primary education almost doubled the risk of having low birth weight which is similar to two studies in khartoum in 2014(20) and 2015(19), However, it is possible that the effect of education on birth weight is, to some extent, a reflection of other influences such as maternal knowledge about proper nutrition and seeking health care services.

Bleeding during pregnancy was found to increase the risk of delivering LBW newborn, this is in consistent with a study in 3 hospitals in Khartoum state (20) but in contrast to a previous study carried out in Omdurman maternity hospital in 2015 (19).Vaginal bleeding during pregnancy is mainly due to problems affecting the uterus and placenta- like placenta previa-, and hence compromise the normal blood flow to the fetus resulting in fetal growth restriction.

Hypertension during pregnancy was found to be significant in inducing LBW in our study. This is in consistent with 2 studies in Khartoum(19) and(20), a study in Ethiopia (26) and a study in Morocco (17). High blood pressure during pregnancy pre-eclampsia- causes placental damage that results in utero-placental insufficiency and hence compromise the feto-placental blood circulation and restrict the fetal growth. 
Urinary tract infection UTI was found as if it have a preventive effect against delivering LBW newborns, as mothers who had been diagnosed with UTI during their pregnancy are two folds less likely to deliver LBW neonates in contrast to a study in Khartoum(19) which stated that prevalence of low birth weight was more among mothers with urinary tract infections. This may be due to that UTI is a diagnosis that needs a health care service and lab facilities to be diagnosed, so those mothers probably had an available access to such services or/and they had the knowledge and willingness to seek it which is in turn had an additional advantage on their pregnancy wellbeing. On the other hand it is unnecessarily that mothers who gave birth to LBW newborns' and claimed that they did not have UTI during their pregnancy were for sure free of the infection, simply they might be not aware about it.

Having malaria or fever during pregnancy was found to be insignificant in our study, this disagree with previous study in the same settings in Khartoum (19), this may be due to the time gap between the two studies and the preventive measures that had been carried out against malaria in between. There was also no significant association between LBW and diabetes during pregnancy.

Adequate spacing( inter-pregnancy spacing of 2 years or more)was found to decrease the chance of delivering LBW neonate by five folds, this is in consistent with many other studies in Ethiopia (10), in India (7) and Khartoum(19), but in contrast to other study done in Khartoum which ignore the role of adequate spacing(20). This could be justified by what called maternal depletion syndrome. It is observed that the energy costs of pregnancy and more of lactation, particularly in the context of frequent reproductive cycles (that is to say, with little or no recovery interval where the woman is not pregnant or lactating), led by an accumulation effect, degradation of maternal nutritional status, and can lead to low birth weight (31). There was no significant association with delivering a LBW neonate and being primagravida or multigravida.

The lack of ANC follow up was found to be significantly associated with LBW in our study, as well the role of adequacy of ANC in affecting LBW is established in many studies (8),(17),(16),(18). This could be explained by the fact that the lack of monitoring of pregnancy does not allow to act on the medical causes of treatable low birth weight or to monitor the results of systematic preventive measures against 
malaria, anemia or nutritional deficiencies which have negative impact on pregnancy. Also ANC guide pregnant ladies toward proper nutritional habits, provide them with iron and other necessary supplements in addition to its important role in early detecting and dealing with pregnancy related conditions and diseases. Whoever the role of ANC in preventing LBW was not found to be significant in studies done in Khartoum, Sudan(19), (20).

Intake of iron supplements during pregnancy was found to have a protective effect with respect to LBW in this study which is consistent with (19) and a study from Nepal (14). Iron is an essential element in hemoglobin synthesis so it's useful in both preventing and treating maternal anemia.

But folic acid supplementation was not significant.

Active smoking during pregnancy, like the previous study in Khartoum, was statistically non-significant risk factor; this may be because active smoking is relatively uncommon among Sudanese women due to the culture. Whoever significant association was found between exposure to passive smoking and giving birth to a LBW neonate.

\section{CHAPTER SIX}

\section{Conclusion}

It has been concluded that LBW found to be associated with that lack of maternal education, rural place of residence, bleeding during pregnancy, high blood pressure during pregnancy, inadequate spacing, lack of ANC follow up, not having iron supplementation and exposure to passive smoking during pregnancy. 


\section{Recommendations}

From a public health perspective, it is an advantage that most of these factors could be modified. Appropriate prevention strategies should be delivered to the high- risk groups ( like women who are residing in rural areas and that who have low level of education). Multifaceted approaches could deliver better services to the pregnant mothers in the area. Such approaches would include health education, motivation of women to increase the use of health care services during pregnancy and improvement in the ANC services. Attendants of ANC should receive disease specific counseling by skilled health personnel with emphasis given to mothers with specific conditions during pregnancy.

Motivation of pregnant mothers for spacing of more than 2 years between two successive pregnancies should be maintained and exposure to tobacco should be avoided by pregnant women.

\section{References:}

1. Asia S. Low Birth Weight Policy Brief. 2012;1-8.

2. Kramer MS. Determinants of low birth weight : methodological assessment and meta-analysis. 1987;65(5):663-737.

3. Geraci M. Morbidity and Mortality in Small for Gestational Age Infants at 22 to 29 Weeks ' Gestation. 2019;141(2).

4. Gu H, Wang L, Lingfei L, Xiu L, Wang J, Hou F, et al. OPEN A gradient relationship between low birth weight and IQ : A meta- analysis. 2017;(March):1-13.

5. Jornayvaz FR, Vollenweider P, Bochud M, Mooser V, Waeber G, Vidal PM. Low birth weight leads to obesity, diabetes and increased leptin levels in 
adults : the CoLaus study. Cardiovasc Diabetol. BioMed Central; 2016;1-10.

6. Low birthweight estimates. 2015;

7. Bendhari M, Haralkar S. Study of maternal risk factors for low birth weight neonates: a case-control study. Int J Med Sci Public Heal. 2015;4(7):987.

8. Sharma SR, Giri S, Timalsina U, Bhandari SS, Basyal B, Wagle K, et al. Low birth weight at term and its determinants in a tertiary hospital of nepal:A casecontrol study. PLoS One. 2015;10(4):1-10.

9. Gebregzabiherher Y, Haftu A, Weldemariam S, Gebrehiwet H. The Prevalence and Risk Factors for Low Birth Weight among Term Newborns in Adwa General Hospital , Northern Ethiopia. 2017;2017(Figure 1).

10. Demelash H, Motbainor A, Nigatu D, Gashaw K, Melese A. Risk factors for low birth weight in Bale zone hospitals, South-East Ethiopia : A case-control study. BMC Pregnancy Childbirth. BMC Pregnancy and Childbirth; 2015;15(1):1-10.

11. Article O. OBSTETRIC RISK FACTORS FOR LOW BIRTH WEIGHT AMONGST FULL TERM BABIES BORN AT A TERTIARY CARE HOSPITAL OF BELGAUM DISTRICT , SOUTH INDIA. 2014;5(1):81-4.

12. Manyeh AK, Kukula V, Odonkor G, Ekey RA, Adjei A, Narh-bana S, et al. Socioeconomic and demographic determinants of birth weight in southern rural Ghana : evidence from Dodowa Health and Demographic Surveillance System. BMC Pregnancy Childbirth [Internet]. BMC Pregnancy and Childbirth; 2016;1-9. Available from: http://dx.doi.org/10.1186/s12884-016-0956-2

13. Dahlui M, Azahar N, Oche OM, Aziz NA, Dahlui M, Azahar N, et al. Risk factors for low birth weight in Nigeria : evidence from the 2013 Nigeria Demographic and Health Survey Risk factors for low birth weight in Nigeria : evidence from the 2013 Nigeria Demographic and Health Survey. 2016;9716.

14. Bhaskar RK, Deo KK, Neupane U, Chaudhary Bhaskar S, Yadav BK, Pokharel HP, et al. A Case Control Study on Risk Factors Associated with Low Birth Weight Babies in Eastern Nepal. Int J Pediatr. 2015;2015:1-7.

15. Id AA, Patil R, Lele P, Choudhari B, Bhattacharjee T. Demographic surveillance over 12 years helps elicit determinants of low birth weights in. 2019;1-14.

16. Raghunath D, Kujur A, Dixit S, Sabnani S. Multivariate Analysis of the Factors affecting Low Birth Weight-A Case-Control Study in a Tertiary hospital of 
Central India. Ann Community Heal. 2017;4(February):18-24.

17. Noureddine E, Abdellatif B. Prevalence and determinants of low birth weight: A case-con-trol study in marrakesh (morocco). Iran J Public Health. 2015;44(3):422-4.

18. Mahumud RA, Sultana M, Sarker AR. Distribution and determinants of low birth weight in developing countries. J Prev Med Public Heal. 2017;50(1):1828.

19. Somiya GSM. Low Birth Weight in Omdurman Maternity Hospital. Int J Sci Res Publ. 2014;4(2):1-13.

20. Saeed OAM, Ahmed HA, Ibrahim AMF, Mahmood EAA, Tasneem O.

Original Article Risk factors of low birth weight at three hospitals in Khartoum State , Sudan. 2014;14(2):22-8.

21. Khan A, Nasrullah FD, Jaleel R. Frequency and risk factors of low birth weight in term pregnancy. Pakistan J Med Sci. 2016;32(1):138-42.

22. Hailu LD, Kebede DL. Determinants of low birth weight among deliveries at a Referral Hospital in Northern Ethiopia. Biomed Res Int. 2018;2018.

23. Kastro S, Demissie T, Yohannes B. Low birth weight among term newborns in Wolaita Sodo town, South Ethiopia : a facility based cross-sectional study. BMC Pregnancy and Childbirth; 2018;1-7.

24. Teklehaimanot N, Hailu T, Assefa H. Prevalence and factors associated with low birth weight in Axum and Laelay Maichew Districts, North Ethiopia : A comparative cross sectional study. 2014;3(6):560-6.

25. Gebremedhin M, Ambaw F, Admassu E, Berhane H. Maternal associated factors of low birth weight : a hospital based cross-sectional mixed study in Tigray, Northern Ethiopia. BMC Pregnancy Childbirth [Internet]. BMC Pregnancy and Childbirth; 2015;1-8. Available from: http://dx.doi.org/10.1186/s12884-015-0658-1

26. Zenebe K, Awoke T, Birhan N. Low Birth Weight \& Associated Factors Among Newborns in Gondar Town, North West Ethiopia : Institutional Based Cross- Sectional Study. 2014;4(2):74-80.

27. Awintuen I, Id A, Kanmiki EW, Nonterah A, Tediosi F, Id JA, et al. Sociodemographic determinants of low birth weight : Evidence from the KassenaNankana districts of the Upper East Region of Ghana. 2018;1-10.

28. Roberto P, Sousa M De, Sarno F. Low birth weight and its associated factors 
Baixo peso ao nascer e seus fatores associados. 2018;16(4):1-6.

29. Abubakari A, Kynast-wolf G, Jahn A. Maternal Determinants of Birth Weight in. $2015 ; 1-15$.

30. Moise KK, Ndala B, Blood D, Mukendi M, René J, Paul CM, et al. Risk Factors of Low Birth Weight in Mbujimayi City, Democratic Republic of Congo. 2017;4.

31. Access O. Facteurs de risque de faible poids de naissance en milieu semi-rural de Kamina, République Démocratique du Congo. 2014;8688:1-5.

32. Metgud CS, Naik VA, Mallapur MD. Factors Affecting Birth Weight of a Newborn - A Community Based Study in Rural Karnataka, India. 2012;7(7).

\title{
Appendices:
}

Questionnaire:

\author{
University of Khartoum \\ Faculty of medicine \\ Department of community medicine
}

Questionnaire assessing the modifiable causes that leads to delivery of full term low birth weight newborns at Omdurman Maternity Hospital 2019 
Identification number:

1- Participant's age:

2- Marital status:
a. married
b. divorced
c. widow
d. single

3- Maternal educational level:

a. primary or no education

b. secondary or above

4- Maternal occupation:
a. occupied
b. not occupied

5- Paternal educational level:
a. primary or no education
b. secondary or above
6- Place of residence:
a. urban area
b. rural area

7-Mother's age at marriage:

8-Monthly income:
a. high
b. moderate
c. low

9- Physical activities during pregnancy at home or outside: 

a. very stressful
b. moderately stressful
c. mildly or not stressful

Do you experience any of the following conditions during the current pregnancy?

10- High blood pressure:
a. yes
b. no

11- Diabetes:
a. yes
b. no

12- Malaria:
a. yes
b. no

\section{3- Fever}
a. yes
b. no

14- Urinary tract infection:

a. yes

b. no

15- how many is your previous deliveries:

16- how long is the mean time between your deliveries:
a. 2 years or more
b. less than 2 years 
17- How old were you at your first delivery:

18- Did you follow up ANC during pregnancy:

a. yes

b. no

19- IF the answer of the previous question was yes, how many was the total of your ANC visits:

20- Were you supplemented with iron supplements during pregnancy:
a. yes
b. no

21- Were you supplemented with folic acid supplement during your pregnancy:
a. yes
b. no

22- Were you smoking during pregnancy:
a- yes
b. no

23- Were you getting exposed to passive smoking during pregnancy:
a. yes
b. no

24- Neonate's weight in grams:

25- Mother's weight in kilograms:

26- Mother's height in meters:

27- Mother's body mass index BMI in $\mathrm{kg} \backslash \mathrm{m} 2$ : 


\section{.}


